\title{
A LIRA ULTRA-ROMÂNTICA: UMA ANÁLISE DOS PROCESSOS DE REFERENCIAÇÃO NA OBRA DE ÁLVARES DE AZEVEDO
}

\author{
Domingos Vieira dos Santos Junior ${ }^{1}$ \\ Deline Maria Fonseca Assunção²
}

\begin{abstract}
RESUMO: A Linguística Textual é o estudo do texto. Uma vez que os textos são formas específicas de manifestação de linguagem, a Linguística Textual ultrapassa os limites de frases e de sentenças e concebe a linguagem como principal ponto de interação. O trabalho intitulado "The lira ultra-romantic: an analysis of referral processes in Álvares de Azevedo work" parte da seguinte problemática: qual a importância dos processos de Referenciação na construção do texto poético? O corpus de análise é a obra Lira dos vinte anos, de Álvares de Azevedo. Os resultados revelam a presença de algumas estratégias no texto poético, como a recategorização, anáfora indireta, anáfora associativa e dêixis de memória que são importantes não só como ponto estético - na utilização de metáforas recategorizadoras, mas também como facilitador da leitura e da compreensão do texto através de diferentes vocábulos - empregadas nas anáforas indiretas e associativas.
\end{abstract}

PALAVRAS-CHAVE: Linguística Textual. Lira dos vinte anos. Referenciação.

\section{INTRODUÇÃO}

O presente trabalho tem como objetivo geral analisar os processos de referenciação na obra Lira dos Vinte Anos, de Álvares de Azevedo. Os objetivos específicos são: verificar os processos de Referenciação, reconhecer a importância dos processos na construção do texto poético e compreender o processo de recategorização para construção de sentido na obra. Para isso, adotamos o referencial teórico da Linguística Textual.

A escolha daLira dos Vinte Anos, de Álvares de Azevedo, principal nome da segunda geração romântica brasileira, deu-se pelo fato de a obra ser toda construída de texto poético, o qual é considerado, por muitos pesquisadores, um texto de difícil entendimento, por ser pessoal e subjetivo, em que, na maioria dos casos, o autor se utiliza de um vasto vocabulário, jogos de palavras, sons e ritmos. Além da forma, tem uma linguagem própria, em que as palavras adquirem significados novos ou diferentes, daqueles que têm noutras tipologias textuais, nomeadas graças aos recursos expressivos utilizados. É rico em figuras de estilo, novas caracterizações e classificações para algo já existente, e, por isso, é

1 Graduado em Letras na Universidade Estadual do Maranhão - UEMA. E-mail: domingosjunior13@outlook.com

2 Mestre em Linguística (UFC) e doutora em Linguística (UFRJ). Professora Adjunto do

Departamento de Letras da UEMA/Campus Caxias. E-mail: delinemfa@hotmail.com

Revista de Letras JUÇARA, Caxias - Maranhão, v. 01, n. 01, p. 37 - 53, Jul. 2017. 
necessário que tenhamos um nível acentuado de leitura para que haja uma melhor compreensão do que se está lendo.

\section{FUNDAMENTAÇÃO TEÓRICA}

\section{Linguística textual}

O termo Linguística Textual surge com Cosériu (1995), embora o sentido que Ihe é atribuído, atualmente, tenha sido empregado pela primeira vez por Weinrich (1967). A Linguística Textual, inicialmente, tinha a proposta de estudar e analisar fenômenos sintáticos-semânticos recorrentes entre enunciados ou sequências, não havendo uma melhor atenção voltada para além dos limites da sentença. Representa, dentro do âmbito da Linguística, um grande avanço no tratamento com unidades menores, palavra, frase ou período, na qual afirmamos que as relações textuais estão além de um pequeno somatório de sintagmas.

Com o desenvolvimento de estudos acerca da Linguística Textual, especificamente a americana, uma nova tendência ganhou espaço na análise das estratégias de referenciação: o estudo do discurso. Dessa forma, aos estudos linguísticos não deveriam apenas estar delimitada a análise gramatical de sistemas linguísticos abstratos ou "ideais"; todavia, preferencialmente, que o uso efetivo da língua deveria ser o objeto empírico das teorias linguísticas.

Levando isso em consideração, temos a Linguística Textual como processo de atividade discursiva que exige dos interlocutores conhecimentos obtidos com base em casos vivenciados socialmente, pois, à medida que isso acontece, tudo o que está sendo armazenado na memória é ativado e garante a compreensão e produção textual.

Agora a Linguística Textual parte da ideia de que toda a ação é acompanhada de processos cognitivos; dessa forma, o falante possui modelos e operações mentais. No caso do texto, levamos em consideração os processos mentais dos quais resultam os textos. De acordo com Koch (2004), os processos da comunicação possuem saberes acumulados quanto aos diversos tipos de atividades da vida social, têm conhecimentos na memória que necessitam ser ativados para que a atividade seja coroada de sucesso. 


\section{Referenciação}

O fenômeno chamado Referenciação tem sido estudado pela Linguística Textual levando em consideração o seu papel de manutenção da coesão e progressão textual. Porém, esse mesmo fenômeno envolve processos cognitivos que, se analisados mais detalhadamente, contribuíram, de forma mais concisa, para a compreensão dos mecanismos de significação dos textos.

O processo de referenciação acontece em tempo e lugar precisos, à medida que envolve participantes determinados. Tais casos ocorrem no discurso através da inserção de expressões que caracterizam um significado, quando associado ao espaço do texto, tendo, assim, uma referência textual.

$\mathrm{Na}$ língua em funcionamento, a Referenciação não se reduz à identificação de objetos da realidade, mas diz respeito ao próprio texto enquanto uma rede em que referentes são introduzidos como objetos de discurso, ou seja, os referentes que se manifestam no discurso, emergindo da negociação dos interlocutores e, como tais, são mantidos, segundo determinadas estratégias dependentes da formulação textual. (APOTHÉLOZ e REICHLER-BÉGUELIN. 1995).

O posicionamento de compreender o mundo em que vivemos, no que tange às línguas, exige vários conceitos cognitivos para, assim, analisarmos os encadeamentos que estruturam o referente e dão um significado ao mundo. Com isso, não questionamos a forma como ocorre a transmissão da mensagem, e sim como a forma como compreendemos esses processos de ação humana, cognitiva e linguística.

Assim, a Referenciação, afirma Mondada e Dubois (2003), é um processo realizado negociadamente no discurso e resulta na construção de referentes de modo que a expressão "referência" passa a ter um uso diverso do que the é atribuído na literatura em geral.

\section{Estratégias de referenciação}

Segundo Van Dijk (2000), processos estratégicos constatam-se com operações baseadas em algoritmos, ou seja, estão fundamentados num conjunto 
preexistente e definido de regras e sistemas, destinados à solução de um problema com um número finito de etapas.

As estratégias expressam possibilidades operacionais eficientes sobre a estrutura e significados corretos de um trecho de texto e podem ser desconfirmadas em processos seguintes.

Tendo abordado os processos estratégicos de referenciação, exemplificaremos nos próximos subtópicos alguns de seus processos.

\section{Anáfora indireta}

A anáfora indireta acontece quando um novo objeto de discurso é inserido no texto e sujeito a ser estabelecido por associação ou inferências.

Marcuschi (1998, p. 217) ressalta seis características das anáforas indiretas:

1) São geralmente constituídas por expressões nominais definidas, indefinidas e pronomes interpretados referencialmente, sem que lhes corresponda um antecedente (ou subsequente) explícito no texto;

2) Trata-se de uma estratégia endofórica (o que já foi dito e/ou o que virá a ser dito no texto) de ativação de referentes novos e não de uma reativação de referentes já conhecidos, o que constitui um caso de referenciação implícita;

3) Frequentes em todos os gêneros textuais, as anáforas podem ancorar cognitivamente em expressões nominais antecedentes que Ihes dão suporte;

4) Como forma de progressão multilinear e não direta, a anáfora indireta reintroduz aspectos sociocognitvos em interface com a semântica e a pragmática (ação prática);

5) São casos de referência textual, isto é, de construção, indução ou ativação de referentes no processo textual-discursivo que envolve atenção cognitiva conjunta de seus interlocutores;

6) Não dependem de uma congruência morfossintática, ou seja, sintonia entre morfologia e sintaxe.

Verifiquemos o exemplo abaixo:

(1) Os olhos eram claros, cor de chumbo, moviam-se devagar, e tinham a expressão dura, seca e fria. (ASSIS, p. 153) 
Aqui, a anáfora indireta é caracterizada pelas relações semânticas dos termos: "claros", "cor de chumbo", "moviam-se devagar", "expressão dura", "seca" e "fria", os quais estarão ancoradas na expressão "os olhos". Ao lermos a sentença é possível que façamos ligações entre os termos para sabermos a quem se referem, estabelecendo relação do termo principal com a sentença.

\section{Anáfora associativa}

As anáforas associativas apresentam seu referente como já conhecido, ou como introduzido no texto, ou seja, sempre que ele não tiver sido ainda objeto de nenhuma menção e que não indicar relação com outros referentes.

Nos atentamos aos exemplos abaixo:

(2) Entrei no restaurante, e ogarçom veio me atender.

(3) Comprei três livros ontem. Os autores estarão fazendo uma sessão de autógrafos amanhã.

O termo referente, na anáfora associativa, não apresenta a mesma entidade que o termo a que se refere. Dessa forma, no exemplo (2) fazemos uma conexão de restaurante com garçom, associando os dois termos, já que é sabido que em um estabelecimento como o restaurante é de praxe que um garçom atenda aos pedidos. Em (3), os autores, retoma o termo livros. Fazemos essa associação através do conhecimento de mundo, pelo qual sabemos que os livros foram escritos por alguém que, aqui, são denominados autores.

\section{Recategorização}

A recategorização é o processo pelo qual os falantes designam os referentes, durante a construção do discurso, selecionando a expressão referencial mais adequada a seus propósitos. Matos (2005 p. 98) define o ato de recategorizar da seguinte forma: 
Entendemos que a recategorização, enquanto estratégia textual interativa, realiza-se por meio de marcas formais, materializadas regularmente nos textos. Por outro lado, coexistem marcas interacionais subjacentes a essa estratégia, porque a recategorização sempre acontece impulsionada por uma intencionalidade do interlocutor, a qual determina o desenvolvimento argumentativo do texto.

É fato que a recategorização é também um processo recorrente nas mais diversas manifestações da linguagem verbal. Com isso, a recategorização é redefinida em Lima (2009, p. 56) da seguinte forma:

A recategorização nem sempre pode ser reconstruída diretamente no nível textual-discursivo, não se configurando apenas pela remissão ou retomada de itens lexicais; a recategorização deve, em alguns casos, ser (re)construída pela evocação de elementos radicados num nível cognitivo, mas sempre sinalizados por pistas linguísticas, para evitar-se extrapolações interpretativas; a recategorização pode ter diferentes graus de explicitude e implicar, necessariamente, processos inferenciais.

Vejamos um exemplo ilustrativo da recategorização:

(4) A rosa de Hiroshima

Pensem nas crianças
Mudas telepáticas
Pensem nas meninas
Cegas inexatas
Pensem nas mulheres
Rotas alteradas
Pensem nas feridas
Como rosas cálidas.
Mas oh não se esqueçam
Da rosa da rosa
Da rosa de Hiroxima
A rosa hereditária
A rosa radioativa
Estúpida inválida
A rosa com cirrose
A anti-rosa atômica
Sem cor sem perfume
Sem rosa sem nada
(Vinícius de Moraes)


A Rosa de Hiroshima, de Vinícius de Moraes, trata do bombardeio nuclear das cidades japonesas de Hiroshima e Nagasaki, o qual provocou a morte de mais de 250 mil pessoas. A partir do título que Vinicius de Moraes utilizou para o poema, é possível perceber o fenômeno da recategorização. No poema, o autor utiliza uma metáfora (Rosa de Hiroshima) para recategorizar o bombardeio. É necessário que tenhamos um prévio conhecimento de mundo para afirmar que, no poema, o formato da rosa, simboliza o desenho formado pela fumaça causada pela explosão da bomba nuclear.

\section{Dêixis}

Ciulla (2002) diz que a dêixis se fundamenta no empréstimo do grego significando "apontar" ou "indicar", ou seja, tal fenômeno conserva o aprontamento e/ou a remissão como característica básica. Tendo em vista esse conceito, palavras ou expressões, quando utilizadas num discurso, adquirem um novo significado, dado o seu referente do contexto.

A dêixis diz respeito à situação de comunicação que envolve os interlocutores (eu/tu), o lugar (aqui, ali, lá) e o tempo (hoje, ontem, amanhã).

O diálogo que segue, apresenta exemplo de dêixis:

(5) Antônia: Eu amanhã encontro-te aqui as 10h. João: Eu não estou disponível! Pode ser de tarde?

No primeiro enunciado, eu significa Antônia; no segundo, eu significa João, tal como o pronome pessoal te do primeiro enunciado. O dêitico amanhã só pode ser corretamente interpretado com o conhecimento do dia em que ocorreu este diálogo, uma vez que significa sempre o dia seguinte ao da enunciação. $O$ dêitico aqui indica o lugar do encontro, informação partilhada somente pelos interlocutores, na situação comunicativa.

\section{Dêixis de memória}

Ciulla (2002, p. 35) afirma que a dêixis de memória constitui exemplo em que o procedimento dêitico dos demonstrativos realiza a sinalização, para o leitor, 
do local onde podem ser encontrados os referentes que, no caso, é o espaço de memória sem qualquer remissão ao contexto.

Vejamos o exemplo dado por Apothéloz (1995):

(6) À noite, vamos ao café. Somos três ou quarto velhos camaradas. Divertimo-nos tomando um trago, queimando nossas gargantas com cachaça! Essa fumaça, esse cheiro de álcool, o barulho das bolas de bilhar, o estampido das rolhas, as gargalhadas, tudo isso ativa meus sentidos e tenho a impressão de que me cresceram.

Ciulla comenta o exemplo da seguinte forma:

O enunciador, ao evocar elementos através das expressões 'essa fumaça' e 'esse cheiro de álcool', trata-os como familiares ao leitor. Porém, no exemplo, além de as expressões dêiticas estarem solicitando uma busca na memória, partindo do pressuposto de que o leitor tem conhecimento de ambientes enfumaçados e cheirando a álcool, elas também encontram suporte no próprio texto, a partir da menção 'café', um local onde normalmente há fumaça e cheiro de álcool (CIULLA, 2002, p. 35).

Percebemos, no exemplo, que o enunciador usa termos-chave para que os interlocutores possam ativar em sua memória lembranças que reportem aos termos citados, aqui classificados de dêixis de memória.

\section{PROCESSOS DE REFERENCIAÇÃO NA OBRA LIRA DOS VINTE ANOS, DE ÁLVARES DE AZEVEDO}

A Lira dos Vinte Anos é a obra mais importante de Álvares de Azevedo, considerado o maior representante do ultrarromantismo no Brasil. Publicada após sua morte, inicialmente, é dividida em duas partes, cada uma com seu prefácio expondo as intenções do autor. A temática de suas poesias é marcada pelo medo de amar, pelas virgens inatingíveis e pelo fascínio pela morte com uma abordagem irônica e satírica em alguns casos.

Seguem a baixo os processos de referenciação analisados no corpus: 


\section{Recategorização}

(7) Crepúsculo do mar

No céu brilhante do poente em fogo

Com auréola ardente o sol dormia:

Do mar doirado nas vermelhas ondas

Purpúreo se escondia.

Como da noite o bafo sobre as águas

Que o reflexo da tarde incendiava,

Só a ideia de Deus e do infinito

No oceano boiava!

Como é doce viver nas longas praias

Nestas ondas e sol e ventania!

Como ao triste cismar encanto aéreo

Nas sombras preludia!

O painel luminoso do horizonte

Como as cândidas sombras alumia

Dos fantasmas de amor que nós amamos

$\mathrm{Na}$ ventura de um dia!

Como voltam gemendo e nebulosas, Brancas as roupas, desmaiado o seio, Inda uma vez a murmurar nos sonhos As palavras do enleio!...

Aqui nas praias onde o mar rebenta E a escuma no morrer os seios rola, Virei sentar-me no silêncio puro Que meu peito consola!

Sonharei - lá enquanto, no crepúsculo, Como um globo de fogo o sol se abisma E o céu lampeja no clarão medonho De nego cataclisma.

Neste exemplo (7), temos um trecho do poema intitulado Crepúsculo do mar, que trata da descrição poética-metafórica de um fenômeno da natureza que 
chamamos de crepúsculo. Para a identificação da re(construção) de um referente já mencionado, é necessário recorrer ao conhecimento enciclopédico de que o crepúsculo é uma luminosidade em cores quentes, de intensidade crescente ao amanhecer e decrescente ao anoitecer. A partir dessa constatação, verificamos que a recategorização do referente crepúsculo, que intitula o poema, é ativada logo no primeiro verso como poente em fogo, que dá uma nova roupagem para o referente do cotexto.

Nos versos seguintes, o autor continua com a temática do poema deixando algumas pistas para que o leitor não se perca diante do que está sendo dito, como por exemplo, os termos "sol", "mar", e a expressões tais como: "reflexo da tarde incendiava", "com auréola o sol dormia". Esses termos e expressões complementam a coerência do poema, permitindo que o leitor fique atento à construção temática. Isto posto, o autor mais uma vez recategoriza o termo crepúsculo utilizando o referente painel luminoso do horizonte. Neste caso, painel está relacionado a um objeto ou espaço bem amplo, luminoso está relacionado ao efeito de luminosidade causada pelo crepúsculo, horizonte é o espaço em que acontece esse fenômeno os quais acrescentam novas características semânticas ao termo inicial.

Na sétima estrofe, o autor retoma o termo crepúsculo usado no título para que, possivelmente, o leitor não perca de vista a temática abordada. Logo em seguida, no próximo verso, ele faz outra recategorização para o termo em discussão: Globo de fogo é a nova expressão referencial, cuja utilização não se deu ao acaso, uma vez que foi construída com elementos inseridos no plano contextual: O sol é uma esfera, tal como o globo (um corpo esférico), e é muito quente, como o fogo. Então, a expressão referencial reconstrói metaforicamente o termo crepúsculo, o que exigirá do leitor conhecimentos enciclopédicos para sua compreensão.

(8) Meu Deus! e assim fizeste a criatura?

Amarraste no lado o peito humano?

Ó poeta, silêncio! é este o homem?

A feitura de Deus! a imagem dele!

O rei da criação!... 
Neste poema (8), percebemos o referente recategorizador rei da criação. A partir dos conhecimentos que vamos adquirindo e arquivando na memória, sabemos que Deus é o criador do céu e da terra; aquele que fez o homem à sua semelhança, assim como também criou todas as espécies vivas (e não vivas) que aqui habitam. Tendo isso em vista, apontamos que o poeta realiza uma recategorização do referente Deus, que, de maneira objetiva e direta, utiliza um novo referente: Rei da criação. Esse referente informa ao leitor quem é esse Deus: aquele que detém o poder sobre todos e sobre tudo. Ainda nesse trecho do poema, o autor recategoriza a palavra feitura, ato de fazer, de dar existência ou forma a, para criação. Assim sendo, a recategorização do referente, no exemplo (8), aciona também no seu efeito informativo, permitindo a identificação da estratégia de referenciação através do contexto.

\section{Anáfora Indireta}

Vejamos, agora, exemplos de anafóricos indiretos retirados da obra Lira dos Vinte Anos:

(9) Quando nas sestas do verão saudoso

A sombra cai nos laranjais do vale

Onde o vento adormece e se perfuma,

E os raios d'oiro, cintilando vivos,

Como a chuva encantada se gotejam

Nas folhas do arvoredo recendente,

Parece que de afã dorme a natura

$E$ as aves silenciosas se mergulham

No grato asilo da cheirosa sombra.

\section{Ó florestas! ó relva amolecida}

A cuja sombra, em cujo doce leito

E tão macio descansar nos sonhos!

Arvoredos do vale! Derramai-me

Sobre o corpo estendido na indolência... 
No exemplo (9), temos o caso de anáfora indireta baseada em relações semânticas. Partimos dessas relações semânticas entre as anáforas e sua âncora e destacamos a expressão natura, no final do $1^{\circ}$ trecho que tem como partes integrantes os termos laranjais do vale, arvoredo, aves, sombra, florestas, relva amolecida, doce leito, arvoredos do vale. As anáforas indiretas remetem à mesma atribuição de referência, ou seja, a natura, no poema, apresenta aves, sombra, floresta etc. Logo, os pontos de ancoragem entre a informação dada e as que surgem possibilitam uma sequência temática e de sentido, o que garante a coerência e a progressão textual.

(10) Ah, vem, ó minha llna: sei harmonias

Que a noite ensina ao violão saudoso

E que a lua do mar influi na mente;

E quando eu vibro as cordas tremulosas,

Como alma de donzela que respira,

Coa nas vibrações tanta saudade...

No exemplo (10), temos o termo âncora violão, instrumento musical que possui um conjunto de cordas que, quando tocadas, emitem vibrações sonoras. $\mathrm{O}$ termo citado ativa um novo esquema anafórico, nesse caso, indiretamente, com os termos cordas e vibrações que estão ancorados semanticamente ao termo inicial violão. Não se trata de entidades necessariamente presentes na noção de violão, mas que podem ser ativadas por esse item na conjugação com conhecimentos de mundo.Com isso, são anafóricos indiretos porque não retomam o referente inicial, mas elementos que dele fazem parte e estão na memória discursiva do leitor/ouvinte.

\section{Dêixis de memória}

(11) [...] Não posso crer um insolente escárnio Do Cavaleiro andante aos nobres sonhos, 
Ao fidalgo da Mancha - cuja nódoa

Foi só ter criado em Deus e amado os homens,

E votado seu braço aos oprimidos.

Aquelas folhas não me causam riso,

Mas desgosto profundo e tédio à vida.

No exemplo (11), a expressão aquelas folhas pode ser considerada como dêixis de memória, pois sinaliza, no poema, através do demonstrativo aquelas, uma lembrança e afirmação da obra de Miguel de Cervantes, Dom Quixote, cuja história é a de um cavaleiro andante, sonhador, que, por ler muitos romances de cavalaria, decidiu incorporar tais heróis para enfrentar dragões e salvar donzelas indefesas. Ao empregar o demonstrativo aquelas, o autor esclarece o seu posicionamento diante da vida do personagem que, para ele, "era um homem que à virtude, amor e cantos abria o coração!" (AZEVEDO, 2006, p. 155), porém foi infeliz na vida.

(12) Numa enorme caldeira enormes peixes,

Recheados capões fervendo ainda,

Perus, olhas-podridas, costeletas...

Esgotara o talento a cozinheira!

Abertos garrafões; garrafas cheias;

Vinho em copos imensos transbordando;

Na toalha, já suja, debruçados

\section{Aqueles religiosos cachaçudos}

De boca aberta e de embotados olhos.

No exemplo (12), temos o trecho de um ato de comédia que segundo os organizadores da Lira dos Vinte Anos, lançada pela editora Martin Claret, em 2006, o autor não concluiu, porém o transformou num poema narrativo, intitulado Boêmios. No trecho utilizado para análise de dêixis de memória, o autor, através do demonstrativo aqueles, recupera informações deixadas no decorrer da narrativa, encapsula e informa quem estava diante daquele banquete que era servido à realeza. 


\section{Anáfora associativa}

(13)[...] Beijarei a verdade santa e nua, Verei cristalizar-se o sonho amigo...

Ó minha virgem dos errantes sonhos,

Filha do céu, eu vou amar contigo!

Descansem o meu leito solitário

$\mathrm{Na}$ floresta dos homens esquecida,

Á sombra de uma cruz, e escrevam nela:

- Foi poeta - sonhou - e amou na vida.-

Sombras do vale, noites da montanha

Que minh' alma cantou e amava tanto,

Protegi o meu corpo abandonado,

E no silêncio derramei-Ihe um canto!

Por ser um texto de cunho poético, é necessário que façamos inferências para percebermos que a sentença, no exemplo (13), floresta dos homens esquecida faz referência ao que nós conhecemos como cemitério. A partir dessa informação, é possível identificarmos a anáfora associativa no termo cruz; acrescentado como sendo parte integrante de um cemitério, o qual foi expresso metaforicamente como floresta dos homens esquecida.

(14) Na praia deserta que a lua branqueia, Que mimo! que rosa! Que filha de Deus! Tão pálida - ao vê meu ser devaneia, Sufoco nos lábios os hálitos meus!

Não corras na areia,

Não corras assim! 
Donzela, onde vais?

Tem pena de mim!

A praia é tão longa! e a onda bravia

As roupas de gaza te molha de escula;

De noite - aos serenos - a areia é tão fria,

Tão úmido o vento que os ares perfuma!

És tão doentia!

Não corras assim!

Donzela, onde vais?

Tem pena de mim!

No exemplo (14), o termo praiadesigna uma entidade diferente dos objetos de discurso que vêm logo em seguida, a areia, a ondae o vento. No entanto, esses três objetos citados apresentam uma relação semântica com sua âncora textual praia, de forma que novos objetos são ativados, reativando, ao mesmo tempo, um objeto que já foi introduzido no texto poético. Dessa forma, caracterizamos essa estratégia de anáfora associativa. Ou seja, esses objetos não são exatamente novos no discurso, nem retomam o item anterior, porém estão ancoradas na existência de uma expressão já mencionada.

Assim, as anáforas associativas referem e evocam a entidade visada a partir de outra especificada pelo antecedente, permitindo "associações", "inferências" como vimos nas anáforas indiretas.

\section{CONCLUSÃO}

O objetivo do nosso trabalho foi analisar os processos de Referenciação na obra Lira dos vinte anos, de Álvares de Azevedo. Nossa análise foi fundamentada na Linguística Textual, mais precisamente nos processos de Referenciação Textual para a construção do objeto de discurso.

Em nosso artigo verificamos, através de análise e amostragem, os processos de referenciação produzidos pelas Recategorizações, Anáforas Indiretas, Anáforas Associativas e Dêixis de Memória constatados na obra em questão. Os processos de referenciação são de extrema importância para a 
construção do texto poético, visto que estes mecanismos também são importantes para que haja uma progressão textual, recuperação e ativação de informações apreendidas através de aspectos cognitivos, o que mantém uma qualidade de sentido em todo o texto.

Assim, no corpus, observamos que os processos de referenciação aqui analisados são, evidentemente, aspectos ou elementos que contribuem para a progressão textual, para a coerência e para a utilização de novos referentes que, a partir de inferências e de conhecimento de mundo puderam ser identificados ao longo da análise. Dessa forma, reafirmamos que a utilização de estratégias de referenciação está associada a progressão textual e sentido da referida obra.

\title{
THE ULTRA-ROMANTIC LIRA: AN ANALYSIS OF REFERRAL PROCESSES IN ÁLVARES DE AZEVEDO WORK
}

\begin{abstract}
Text Linguistics is the study of the text. Considering that texts are specific forms of language manifestation, Text Linguistics goes beyond the limits of clauses and sentences, and the language is the main point of interaction. This paper entitled "The lira ultra-romantic: an analysis of referral processes in Álvares de Azevedo work" starts from the following problematic: what is the referencing process in the construction of the poetic text? The corpus of analysis is Twenty-yearold Lyre, by Álvares de Azevedo. The results show the presence of some strategies in the poetic text, such as the recategorization, indirect anaphora associative anaphora as deixis memory that are important not only as an aesthetic point - in the use of metaphors for recategorization - but also as a facilitator of the reading and comprehension of the text through different words, used in indirect and associative anaphora.
\end{abstract}

KEYWORDS: Text Linguistics. Twenty-year-old Lyre. Reference.

\section{REFERÊNCIAS}

APOTHÉLOZ, Denis; REICHLER-BÉGUELIN, M. J. Construction de la référence et strategies de desigation. TRANEL (travaux neuchâtelois de linguistique) 23,1995, pp. 227-271.

ASSIS, Machado de. A causa secreta. Obra completa. Rio de Janeiro: Nova Aguilar, 1986. v. 2.

AZEVEDO, Álvares de. Lira dos Vinte anos. São Paulo: Martin Claret, 2006.

CAVALCANTE, Mônica Magalhães; BRITO, Mariza Angélica Paiva (Orgs.). Gêneros textuais e referenciação. Fortaleza: Protexto, 2004. CD-rom. 
CIULLA, Alena. A referenciação anafórica e dêitica: com atenção especial para os dêiticos discursivos. Fortaleza, 2002, 98f. Dissertação (Mestrado em Linguística). Centro de Humanidades, Universidade Federal do Ceará, Fortaleza, 2002.

COSÉRIU, E. Determinación y entorno: de los problemas de uma linguística dei hablar. Romanistisches Jahrbuch, n. 7, 1995. pp. 29-54.

LIMA, S.M.C. Entre os domínios da metáfora e metonímia: um estudo de processos de recategorização. 2009. 205f. Tese (Doutorado em Linguística) Centro de Humanidades, Universidade Federal do Ceará, Fortaleza, 2009.

MARCUSCHI, Luiz Antônio. Aspectos linguísticos, sociais e cognitivos da produção de sentido. GELNE. Natal, RN, v.1, n.1,1998, p. 2.

MATOS, Janaíca Gomes. As funções discursivas das recategorizações. 2005, 142f. Dissertação (Mestrado em Linguística) - Centro de Humanidades, Universidade Federal do Ceará, Fortaleza 2005.

MONDADA E DUBOIS, D. Construction des objets de discours et categorisation: une approche des processos de referentiation. In: BERRENDONNER, A.; BEGUELIN, M-J. Reichler. Du sintagme nominal aux objets-de-discours. Neuchatel: Université de Neuchatel, 1995, pp. 273-302.

MONDADA, L.; DUBOIS, D. Construção dos objetos de discurso e categorização:uma abordagem dos processos de referenciação. Cavalcante. In: CAVALCANTE, M.M.; RODRIGUES, B.B.; CIULLA, A. (Orgs). Referenciação. São Paulo: Contexto. 2003. pp.17-52.

KOCH.I. G. V.Introdução à linguística textual: trajetória e grandes temas. São Paulo: Martins Fontes, 2004. Disponível em: <http://docslide.com.br/documents/koch-i-g-v-introdução-a-linguistica-textual.html> Acesso em: 23/11/2015.

VAN DIK. Cognição, discurso e interação. (Org. Ingedore V. Koch). 3. ed. São Paulo: Contexto, 2000.

WEINRICH, H. Linguistik der Luge. Heidelberg: Verlag Lambert Schneider, 1967

Data de Submissão: 05/03/17

Data de Aprovação: 06/05/17 